\title{
Combination of Newton-Halley-Chebyshev Iterative Methods Without Second Derivatives
}

\author{
Ahmad Syakir, M. Imran, Moh Danil Hendry Gamal \\ Department of Mathematics, University of Riau, Pekanbaru, Indonesia \\ Email address: \\ hr.syakir@gmail.com (A. Syakir),mimran@unri.ac.id (M. Imran),mdhgamal@unri.ac.id (M. D. H. Gamal)
}

\section{To cite this article:}

Ahmad Syakir, M. Imran, Moh Danil Hendry Gamal. Combination of Newton-Halley-Chebyshev Iterative Methods Without Second Derivatives. International Journal of Theoretical and Applied Mathematics. Vol. 3, No. 3, 2017, pp. 106-109.

doi: 10.11648/j.ijtam.20170303.12

Received: April 11, 2017; Accepted: April 21, 2017; Published: May 19, 2017

\begin{abstract}
This article discusses the modification of three step iteration method to solve nonlinear equations $f(x)=0$. The new iterative method is formed from a combination of Newton, Halley, and Chebyshev methods. To reduce the number of evaluation functions, some derivatives in this method are estimated by Taylor polynomials. Using analysis of convergence we show that the new method has the order of convergence fourteen. Numerical computation shows that the new method are comparable to other methods discussed.
\end{abstract}

Keywords: Free Second Derivative Method, Taylor Series, Iterative Method, Order of Convergence

\section{Introduction}

Nonlinear equation is an important discussion in numerical analysis. A method of finding a solution of nonlinear equation is one of the topics that is often discussed in numerical analysis literatures. A nonlinear equation is presented in the form

$$
f(x)=0 .
$$

The solution of nonlinear equation (1) can be found in various ways, among others use the iterative methods. The solution by an iterative method gives a good approach to the true solution.

Let $\alpha$ be a solution of nonlinear equation (1), if $x_{n}$ is a given initial value then nonlinear equation (1) can be approached by using Taylor expansion of $f(x)$ about $x=x_{n}$ by

$$
f(x)=f\left(x_{n}\right)+f^{\prime}\left(x_{n}\right)\left(x-x_{n}\right)+\frac{f^{\prime \prime}\left(x_{n}\right)\left(x-x_{n}\right)^{2}}{2 !}+\cdots
$$

First two terms of the equation (2) give an iterative method that is often used to solve nonlinear equation (1). The method is as follows:

$$
x_{n+1}=x_{n}-\frac{f\left(x_{n}\right)}{f^{\prime}\left(x_{n}\right)}, f^{\prime}\left(x_{n}\right) \neq 0, n=0,1,2, \ldots
$$

The iterative method (3) is known as Newton's method having quadratically convergence [1]. Some modifications of Newton's method have been made in some papers $[7,14]$ to increase the convergency.

Then from three terms of (2) we get an iterative method having cubically convergence as follows:

$$
x_{n+1}=x_{n}-\frac{2 f\left(x_{n}\right) f^{\prime}\left(x_{n}\right)}{2 f^{\prime}\left(x_{n}\right)^{2}-f\left(x_{n}\right) f^{\prime \prime}\left(x_{n}\right)}, n=0,1,2, \ldots
$$

Iterative method (4) is known as Halley's method. The method (4) has been developed and discussed in some papers $[5,6,8,11,12]$ so as to produce a diverse order of convergence.

Then by using different algebraic manipulation of (2), another iterative method is obtained in the form

$$
x_{n+1}=x_{n}-\frac{f\left(x_{n}\right)}{f^{\prime}\left(x_{n}\right)}-\frac{f^{2}\left(x_{n}\right) f^{\prime \prime}\left(x_{n}\right)}{2 f^{\prime}\left(x_{n}\right)^{3}}, n=0,1,2, \ldots
$$

The iterative method (5) is known as Chebyshev's method having cubically convergence [4].

Then from three iterative methods (3), (4) and (5), Bahgat and Hafiz [2] introduce an iterative method to solve nonlinear equation. The iterative method is defined by

$$
y_{n}=x_{n}-\frac{f\left(x_{n}\right)}{f^{\prime}\left(x_{n}\right)^{\prime}}
$$




$$
\begin{aligned}
& z_{n}=y_{n}-\frac{2 f\left(y_{n}\right) f^{\prime}\left(y_{n}\right)}{2 f^{\prime}\left(y_{n}\right)^{2}-f\left(y_{n}\right) f^{\prime \prime}\left(y_{n}\right)^{\prime}} \\
& x_{n+1}=z_{n}-\frac{f\left(z_{n}\right)}{f^{\prime}\left(z_{n}\right)}-\frac{f^{2}\left(z_{n}\right) f^{\prime \prime}\left(z_{n}\right)}{2 f^{\prime}\left(z_{n}\right)^{3}},
\end{aligned}
$$

In this article we discusse an iterative method without second derivative to solve nonlinear equation (1). The discussed method is obtained by changing the calculation of function $f^{\prime \prime}\left(z_{n}\right)$ at (8) by $f^{\prime \prime}\left(y_{n}\right)$. Then $f^{\prime \prime}\left(y_{n}\right)$ is approached by Taylor polynomial. In section 3 we present the numerical computation of some test functions.

\section{Proposed Methods}

Newton-Halley-Chebyshev's iterative method without second derivatives is a modification of Bahgat-Hafiz's method (6) by changing the calculation of function $f^{\prime \prime}\left(z_{n}\right)$ in equation (6) by $f^{\prime \prime}\left(y_{n}\right)$. The equation (6) can be written as

$$
\begin{gathered}
y_{n}=x_{n}-\frac{f\left(x_{n}\right)}{f^{\prime}\left(x_{n}\right)^{\prime}} \\
z_{n}=y_{n}-\frac{2 f\left(y_{n}\right) f^{\prime}\left(y_{n}\right)}{2 f^{\prime}\left(y_{n}\right)^{2}-f\left(y_{n}\right) f^{\prime \prime}\left(y_{n}\right)^{\prime}} \\
x_{n+1}=z_{n}-\frac{f\left(z_{n}\right)}{f^{\prime}\left(z_{n}\right)}-\frac{f^{2}\left(z_{n}\right) f^{\prime \prime}\left(y_{n}\right)}{2 f^{\prime}\left(z_{n}\right)^{3}},
\end{gathered}
$$

Then $f^{\prime \prime}\left(y_{n}\right)$ in equations (10) and (11) are approached by a polynomial obtained using Taylor expansion of $f(x)$ and $f^{\prime}(x)$ about $x=y_{n}$ up to third derivative, then $f(x)$ and $f^{\prime}(x)$ are evaluated in $x=x_{n}$, after the simplification we have

$$
\begin{gathered}
f^{\prime \prime}\left(y_{n}\right) \approx \frac{2}{y_{n}-x_{n}}\left(2 f^{\prime}\left(y_{n}\right)+f^{\prime}\left(x_{n}\right)-3 \frac{f\left(y_{n}\right)-f\left(x_{n}\right)}{y_{n}-x_{n}}\right)= \\
P_{f}\left(x_{n}, y_{n}\right) .
\end{gathered}
$$

By substituting (12) into (10) and (11) we have the iterative method is as follows:

$$
\begin{gathered}
y_{n}=x_{n}-\frac{f\left(x_{n}\right)}{f^{\prime}\left(x_{n}\right)^{\prime}} \\
z_{n}=y_{n}-\frac{2 f\left(y_{n}\right) f^{\prime}\left(y_{n}\right)}{2 f^{\prime}\left(y_{n}\right)^{2}-f\left(y_{n}\right) P_{f}\left(x_{n}, y_{n}\right)^{\prime}} \\
x_{n+1}=z_{n}-\frac{f\left(z_{n}\right)}{f^{\prime}\left(z_{n}\right)}-\frac{f^{2}\left(z_{n}\right) P_{f}\left(x_{n}, y_{n}\right)}{2 f^{\prime}\left(z_{n}\right)^{3}},
\end{gathered}
$$

In Theorem 1 we show the convergence of iterative method (13)-(15).

Theorem 1 (Order of Convergence) Let $f: D \rightarrow \mathbb{R}$ be a differentiable function in an open interval $D$. Then assume that $\alpha$ is a simple root of $f(x)=0$. Suppose $x_{0}$ is a given initial value that is sufficiently close to $\alpha$, then iterative method (13)-(15) have the order of convergence fourteen and satisfying the following error equation:

$$
\begin{aligned}
e_{n+1}=\left(7 c_{2}^{6} c_{4} c_{3}^{2}\right. & +c_{2}^{4} c_{4}^{3}-5 c_{2}^{5} c_{3} c_{4}^{2}+2 c_{2}^{7} c_{4}^{2}-3 c_{2}^{7} c_{3}^{3} \\
& \left.+6 c_{2}^{9} c_{3}^{2}+c_{2}^{10} c_{4}-3 c_{2}^{11} c_{3}-8 c_{2}^{8} c_{3} c_{4}\right) e_{n}^{14} \\
& +O\left(e_{n}^{15}\right)
\end{aligned}
$$

Proof. Let $\alpha$ be a simple root of the equation $f(x)=0$, then $f(\alpha)=0$ and $f^{\prime}(\alpha) \neq 0$. By using Taylor expansion of $f(x)$ and $f^{\prime}(x)$ about $x=\alpha, f(x)$ and $f^{\prime}(x)$ are evaluated in $x=x_{n}$ so that we have

$$
f\left(x_{n}\right)=f^{\prime}(\alpha)\left(e_{n}+c_{2} e_{n}^{2}+c_{3} e_{n}^{3}+\cdots\right),
$$

and

$$
f^{\prime}\left(x_{n}\right)=f^{\prime}(\alpha)\left(1+2 c_{2} e_{n}+3 c_{3} e_{n}^{2}+\cdots\right),
$$

where $e_{n}=x_{n}-\alpha$ and $c_{k}=\frac{f^{(k)}(\alpha)}{k ! f^{\prime}(\alpha)}, k=2,3, \ldots$. If (16) is divided by (17) then we have

$$
\frac{f\left(x_{n}\right)}{f^{\prime}\left(x_{n}\right)}=e_{n}-c_{2} e_{n}^{2}+2\left(c_{2}^{2}-c_{3}\right) e_{n}^{3}+\cdots
$$

By substituting (18) into (13) and $x_{n}=\alpha+e_{n}$ is given we have

$$
y_{n}=\alpha+c_{2} e_{n}^{2}+2\left(c_{3}-c_{2}^{2}\right) e_{n}^{3}+\cdots .
$$

By using (19) and applying Taylor expansion of $f(y)$ and $f^{\prime}(y)$ about $y=\alpha, f(y)$ and $f^{\prime}(y)$ are evaluated in $y=y_{n}$. After simplification we have

$$
f\left(y_{n}\right)=f^{\prime}(\alpha)\left(c_{2} e_{n}^{2}+2\left(c_{3}+c_{2}^{2}\right) e_{n}^{3}+\cdots\right),
$$

and

$$
f^{\prime}\left(y_{n}\right)=f^{\prime}(\alpha)\left(1+2 c_{2}^{2} e_{n}^{2}+\cdots\right) .
$$

From (20) and (21) doing calculation for $2 f\left(y_{n}\right) f^{\prime}\left(y_{n}\right)$, after simplification, we get

$$
2 f\left(y_{n}\right) f^{\prime}\left(y_{n}\right)=f^{\prime}(\alpha)^{2}\left(2 c_{2}^{2} e_{n}^{2}+4\left(c_{3}-c_{2}^{2}\right) e_{n}^{3}+\cdots\right) .
$$

Furthermore from (21) we have

$$
2 f^{\prime}\left(y_{n}\right)^{2}=f^{\prime}(\alpha)^{2}\left(2+8 c_{2}^{2} e_{n}^{2}+\cdots\right) .
$$

Then $P_{f}\left(x_{n}, y_{n}\right)$ at (12) is calculated by substituting (16), (17), (19), (20), and (21) into (12) and $x_{n}=\alpha+e_{n}$ is given we obtain

$$
P_{f}\left(x_{n}, y_{n}\right)=f^{\prime}(\alpha)\left(2 c_{2}+\left(6 c_{2} c_{3}+2 c_{4}\right) e_{n}^{2}+\cdots\right) .
$$

If (20) is multiplied by (24), we obtain

$$
f\left(y_{n}\right) P_{f}\left(x_{n}, y_{n}\right)=f^{\prime}(\alpha)^{2}\left(2 c_{2}^{2} e_{n}^{2}+\left(4 c_{2} c_{3}-4 c_{2}^{3}\right) e_{n}^{3}+\cdots\right)
$$

By substituting (19), (22), (23), and (25) into (14), after simplification, we have

$$
z_{n}=\alpha+\left(c_{2}^{2} c_{4}+c_{2}^{5}-c_{2}^{3} c_{3}\right) e_{n}^{6}+\cdots .
$$

Then by using (26) and applying Taylor expansion of $f(z)$ and $f^{\prime}(z)$ about $z=\alpha, f(z)$ and $f^{\prime}(z)$ are evaluated in $z=z_{n}$, after simplification, we have

$$
f\left(z_{n}\right)=f^{\prime}(\alpha)\left(\left(c_{2}^{2} c_{4}+c_{2}^{5}-c_{2}^{3} c_{3}\right) e_{n}^{6}+\cdots\right),
$$

and

$$
f^{\prime}\left(z_{n}\right)=f^{\prime}(\alpha)\left(1+\left(2 c_{2}^{3} c_{4}+c_{2}^{6}-2 c_{2}^{4} c_{3}\right) e_{n}^{6}+\cdots\right) .
$$


Dividing (27) by (28) we get

$$
\frac{f\left(z_{n}\right)}{f^{\prime}\left(z_{n}\right)}=\left(c_{2}^{2} c_{4}+c_{2}^{5}-c_{2}^{3} c_{3}\right) e_{n}^{6}+\cdots
$$

If (27) is squared and then multiplied by (24) we have

$$
\begin{gathered}
f\left(z_{n}\right)^{2} P_{f}\left(x_{n}, y_{n}\right)=f^{\prime}(\alpha)^{3}\left(\left(4 c_{2} 8 c_{4}+c_{2}^{7} c_{3}^{2}+2 c_{2}^{5} c_{4}^{2}+\right.\right. \\
\left.\left.2 c_{2}^{11}-4 c_{2}^{6} c_{3} c_{4}-4 c_{2}^{9} c_{3}\right) e_{n}^{12}+\cdots\right)
\end{gathered}
$$

Then from (28), doing calculation for $f\left(z_{n}\right)^{3}$ and we have

$$
x_{n+1}=\alpha+\left(7 c_{2}^{6} c_{4} c_{3}^{2}+c_{2}^{4} c_{4}^{3}-5 c_{2}^{5} c_{3} c_{4}^{2}+2 c_{2}^{7} c_{4}^{2}-3 c_{2}^{7} c_{3}^{3}+6 c_{2}^{9} c_{3}^{2}+c_{2}^{10} c_{4}-3 c_{2}^{11} c_{3}-8 c_{2}^{8} c_{3} c_{4}\right) e_{n}^{14}+O\left(e_{n}^{15}\right)
$$

Since $e_{n+1}=x_{n+1}-\alpha$,

$$
e_{n+1}=\left(7 c_{2}^{6} c_{4} c_{3}^{2}+c_{2}^{4} c_{4}^{3}-5 c_{2}^{5} c_{3} c_{4}^{2}+2 c_{2}^{7} c_{4}^{2}-3 c_{2}^{7} c_{3}^{3}+6 c_{2}^{9} c_{3}^{2}+c_{2}^{10} c_{4}-3 c_{2}^{11} c_{3}-8 c_{2}^{8} c_{3} c_{4}\right) e_{n}^{14}+O\left(e_{n}^{15}\right)
$$

From the definition of the order of convergence [9], this ends the proof of the method (13)-(15). So, the method has the order of convergence fourteen.

\section{Numerical Expriments}

In this section, we present the numerical computation to compare the number of iterations and the order of convergence of Bahgat-Hafiz's method (MB) in (6)-(8), Rafiullah-Haleem's method (RH) [13], Matinfar et al.'s method (MAA) [10], and Newton-Halley-Chebyshev's method without second derivatives (NHC) (13)-(15) to find the solution of nonlinear equation. Tolerance is given by 1.0 $\mathrm{x} 10^{-50}$. The criteria to stopping the computing program is if $\left|f\left(x_{n+1}\right)\right| \leq$ Tolerance, $\left.\mid x_{n}-x_{n-1}\right) \mid \leq$ Tolerance, or the number of iterations reaches 100 iterations. Table 1 givens some nonlinear equations as test functions.

In Table 2, first column shows some test functions denoted by $f$, second column includes initial value denoted by $x_{0}$ and some iterative methods, third column is number of iterations of each method, fourth column is absolute value of test function for root approximation to $n$, fifth column is difference of absolute value between two adjacent roots, and sixth column is computational order of convergence (COC) of each method. The symbol $\bullet$ in iteration column shows that the resulting number of iterations exceeds the maximum number of iterations specified. The symbol * shows that the iterative method convergent to other root. The symbol $\mathrm{NaN}$ represents the computational results that cannot be expressed numerically.

In Table 2 we have the first function $\left(f_{1}\right)$ with initial value $x_{0}=1.5$ and $x_{0}=2.6$. All of comparison methods are convergent to the approximation root and there is no significant difference of number of iterations of each method.

The second function $\left(f_{2}\right)$ for $x_{0}=-0.3$, all of comparison methods convergent to predetermined root. However the number of iterations of $\mathrm{MB}$ and $\mathrm{NHC}$ less than the others, i.e. two iterations. Then for $x_{0}=0.6$, only NHC converges to the predetermined root. While the three other methods $\mathrm{MB}, \mathrm{RH}$, and MAA are not convergent.

The third function $\left(f_{3}\right)$ for initial value $x_{0}=-1.2$, the visible difference is in the number of iterations of $\mathrm{RH}$ and others. While thenumber of iterations of MB exceeds the maximum number of iterations specified. Then for initial value $x_{0}=2.0$, all of methods are convergent.

The fourth function $\left(f_{4}\right)$ for initial value $x_{0}=-0.6$, all the methods are convergent. Then for $x_{0}=1.1$, MAA is the only method that does not convergent to predetermined root, since $f_{4}$ has two roots.

From computational order of convergence (COC) of each method with different initial values, $\mathrm{MB}$ and $\mathrm{NHC}$ has a convergency higher order than others, so that $\mathrm{MB}$ and $\mathrm{NHC}$ move faster in reaching the root of nonlinear equation. For overall, from all compared functions, it can be seen that NHC is better than other methods discussed, so that NHC method may be considered as a method to find a root of nonlinear equation.

Table 1. Some test function and the roots $(\alpha)$ of each function.

\begin{tabular}{ll}
\hline Test function & $\boldsymbol{\alpha}$ \\
\hline$f_{1}(x)=x^{3}-10$ & 2.15443469003188372175929356651935049525934494219210 \\
$f_{2}(x)=10 x e^{-x^{2}}-1$ & 0.10102584831568519736756321568689232174299669891262 \\
$f_{3}(x)=\cos (x)-x$ & 0.73908513321516064165531208767387340401341175890075 \\
$f_{4}(x)=\sin (x)-e^{x}+3 x$ & 0.36042170296032440136932951583028126563669677955004 \\
\hline
\end{tabular}

Table 2. Comparison of the computational results of some iterative methods.

\begin{tabular}{lllll}
\hline Function & Method & Iteration & $\left|\boldsymbol{f}\left(\boldsymbol{x}_{\boldsymbol{n}}\right)\right|$ & $\left|\boldsymbol{x}_{\boldsymbol{n}}-\boldsymbol{x}_{\boldsymbol{n}-\mathbf{1}}\right|$ \\
\hline & $x_{0}=1.5$ & & & $\boldsymbol{C O C}$ \\
$f_{1}(x)$ & MB & 2 & $4.17773166 \mathrm{e}-143$ & $2.28216431 \mathrm{e}-08$ \\
& RH & 4 & $8.78308099 \mathrm{e}-234$ & $1.50417300 \mathrm{e}-39$ \\
& MAA & 3 & $4.86246493 \mathrm{e}-141$ & $3.82025284 \mathrm{e}-18$ \\
& NHC & 2 & $8.60453184 \mathrm{e}-88$ & $1.08151455 \mathrm{e}-06$ \\
\hline
\end{tabular}




\begin{tabular}{|c|c|c|c|c|c|}
\hline Function & Method & Iteration & $\left|f\left(x_{n}\right)\right|$ & $\left|x_{n}-x_{n-1}\right|$ & COC \\
\hline \multirow{14}{*}{$f_{2}(x)$} & MB & 2 & $2.28840202 \mathrm{e}-245$ & $4.75507708 \mathrm{e}-14$ & 17.9206 \\
\hline & RH & 3 & $1.08014835 \mathrm{e}-148$ & $2.28526838 \mathrm{e}-25$ & 6.0000 \\
\hline & MAA & 3 & $7.49779062 \mathrm{e}-406$ & $3.02413873 e-51$ & 8.0000 \\
\hline & $\mathrm{NHC}$ & 2 & $8.32765019 \mathrm{e}-150$ & $4.02204067 \mathrm{e}-11$ & 13.9209 \\
\hline & $x_{0}=-0.3$ & & & & \\
\hline & MB & 2 & $1.76595237 \mathrm{e}-161$ & $1.82722905 \mathrm{e}-09$ & 18.3425 \\
\hline & RH & 3 & $1.54118174 \mathrm{e}-87$ & $2.94475032 \mathrm{e}-15$ & 5.9998 \\
\hline & MAA & 3 & $1.81786603 e-199$ & $1.25865079 \mathrm{e}-25$ & 7.9998 \\
\hline & NHC & 2 & $2.08222680 \mathrm{e}-94$ & $3.61445044 e-07$ & 14.5946 \\
\hline & $x_{0}=0.6$ & & & & \\
\hline & MB & 3 & $\mathrm{NaN}$ & $\mathrm{NaN}$ & $\mathrm{NaN}$ \\
\hline & RH & 4 & $\mathrm{NaN}$ & $\mathrm{NaN}$ & $\mathrm{NaN}$ \\
\hline & MAA & 3 & $\mathrm{NaN}$ & $\mathrm{NaN}$ & $\mathrm{NaN}$ \\
\hline & $\mathrm{NHC}$ & 3 & $3.79549365 e-76$ & $7.28394030 \mathrm{e}-06$ & 14.9069 \\
\hline \multirow{9}{*}{$f_{3}(x)$} & $x_{0}=-1.2$ & & & & \\
\hline & MB & i & • & - & $*$ \\
\hline & RH & 13 & $1.72039150 \mathrm{e}-148$ & $5.49202499 \mathrm{e}-25$ & 6.0000 \\
\hline & MAA & 3 & $1.01497197 \mathrm{e}-90$ & $1.92151642 \mathrm{e}-11$ & 7.9933 \\
\hline & $\begin{array}{l}\mathrm{NHC} \\
x_{0}=2.0\end{array}$ & 4 & $1.75580808 \mathrm{e}-195$ & $4.78420866 \mathrm{e}-14$ & 14.0981 \\
\hline & $\mathrm{MB}$ & 2 & $5.16841071 \mathrm{e}-454$ & $2.15048866 e-25$ & 17.3143 \\
\hline & RH & 3 & $1.45972004 \mathrm{e}-131$ & $3.64059933 e-22$ & 6.0001 \\
\hline & MAA & 2 & $2.84756489 \mathrm{e}-63$ & $5.18377980 \mathrm{e}-08$ & 7.5120 \\
\hline & NHC & 2 & $4.50077108 e-219$ & $9.87927567 \mathrm{e}-16$ & 13.4758 \\
\hline \multirow{10}{*}{$f_{4}(x)$} & $x_{0}=-0.6$ & & & & \\
\hline & MB & 2 & $1.41381566 e-231$ & $3.08062240 \mathrm{e}-13$ & 17.5076 \\
\hline & RH & 3 & $3.29209416 e-129$ & $5.64103371 \mathrm{e}-22$ & 6.0001 \\
\hline & MAA & 3 & $1.63382997 e-290$ & $1.06410081 \mathrm{e}-36$ & 8.0000 \\
\hline & NHC & 2 & $5.41296870 \mathrm{e}-130$ & $1.12100172 \mathrm{e}-09$ & 13.5135 \\
\hline & $x_{0}=1.1$ & & & & \\
\hline & $\mathrm{MB}$ & 3 & $0.00000000 \mathrm{e}+00$ & $7.82393793 e-48$ & 10.1031 \\
\hline & RH & 5 & $4.35615419 \mathrm{e}-78$ & $1.86909135 \mathrm{e}-13$ & 5.9967 \\
\hline & MAA & 3 & $1.43430288 \mathrm{e}-145$ & $8.15441571 \mathrm{e}-19$ & * \\
\hline & NHC & 3 & $3.90024618 e-265$ & $2.49219342 \mathrm{e}-19$ & 13.9726 \\
\hline
\end{tabular}

\section{Conclusions}

In this paper we present the modify of Bahgat-Hafiz's method by removing the second derivative using Taylor polynomial. This method requires three functions and three first derivative evaluations per iteration. We have that the order convergence of this method is fourteen. Analysis of the efficiency shows that this method is better than BahgatHafiz's method, and some discussed methods.

\section{References}

[1] K. E. Atkinson, Elementary Numerical Analysis, third Ed., John Wiley \& Sons, Inc., New York, 1993.

[2] M. S. M. Bahgat and M. A. Hafiz, Three step iterative method with eighteenth order convergence for solving nonlinear equations, International Journal of Pure and Applied Mathematics, 93 (2014), 85-94.

[3] R. Behl and V. Kanwar, Variant of Chebyshev's methods with optimal order convergence, Tamsui Oxford Journal of Information and Mathematical Sciences, 29 (2013), 39-53.

[4] M. A. Hafiz, An efficient three step tenth order method without second order derivative, Palestine Journal of Mathematics, 3 (2014), 198-203.

[5] M. A. Hafiz and S. M. H. Al-Goria, New ninth and seventh order methods for solving nonlinear equations, Europian Scientific Journal, 8 (2012), 83-95.

[6] R. King, A family of fourth order methods for nonlinear equations, Journal of Numerical Analysis, 10 (1973), 876-879.

[7] J. Kou, Y. Li, and X. Wang, Modified Halley's method free from second derivative, Applied Mathematics and Computation, 183 (2006), 704-708.

[8] J. H. Mathews and K. D. Fink, Numerical Methods Using MATLAB, third Ed., Prentice Hall, New Jersey, 1999.

[9] M. Matinfar, M. Aminzadeh, and S. Asadpour, A new three step iterative method for solving nonlinear equations, Journal of Mathematical Extension, 6 (2012), 29-39.

[10] K. I. Noor and M. A. Noor, Predictor-corrector Halley method for nonlinear equations, Applied Mathematics and Computation, 188 (2007), 1587-1591.

[11] M. A. Noor, W. A. Khan, and A. Hussain, A new modified Halley method without second derivatives for nonlinear equations, Applied Mathematics and Computation, 189 (2007), 1268-1273.

[12] M. Rafiullah and M. Haleem, Three step iterative method with sixth order convergence for solving nonlinear equations, International Journal of Mathematic Analysis, 50 (2010), 2459-2463.

[13] G. Zavalani, A modification of Newton method with third order convergence, American Journal of Numerical Analysis, 2 (2014), 98-101. 